\title{
Prevalence and Spectrum of Coronary Anomalies Detected on Coronary Computed Tomography Angiography A single centre experience in Oman
}

$$
\text { معدل انتشار وأنواع الشذوذ الحلقية للشرايين التاجية المكتشفة باستخدام التحوير المقطعي المبربة مركز واحد في سلطنة عمان للاوعية الدموية }
$$

$$
\text { راشد سيف العمري، فايزة الكندي، صقر الطائي }
$$

ABSTRACT: Objectives: Coronary artery anomalies (CAAs) are uncommon congenital abnormalities with a prevalence ranging from $0.2-2 \%$. CAAs can be asymptomatic or less commonly present with life-threatening symptoms. This study aimed to investigate the prevalence and spectrum of CAAs in patients who underwent coronary computed tomography angiography (CCTA) in Oman. Methods: This retrospective study was conducted at the National Heart Centre, Muscat, Oman between September 2012 and August 2018. All consecutive patients who had undergone CCTA were included. Results: A total of 4,445 patients were included in this study. Of these, 59 patients (1.3\%) were diagnosed with CAAs with a mean age of 52.6 years (range: $12-80$ years) and an equal gender distribution. Among the patients with CAAs, the majority (69.5\%) had anomalous origins from the opposite or non-coronary sinus. Right coronary artery arising from the left coronary sinus was the most common type (33.9\%). Fewer patients (18.6\%) had left circumflex arising from the right coronary sinus (RCS). Seven patients (11.9\%) had left main arising from the RCS. Other CAAs were in the dual left anterior descending artery (8.5\%), high coronary artery take-off (6.8\%), single coronary ostia (6.8\%) and coronary artery fistula (6.8\%). Conclusion: The prevalence of CAAs was $1.3 \%$ which is similar to the literature.

Keywords: Coronary Vessel Anomalies; Computed Tomography Angiography; Prevalence; Oman.

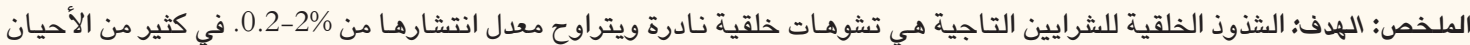

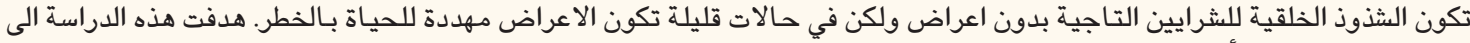

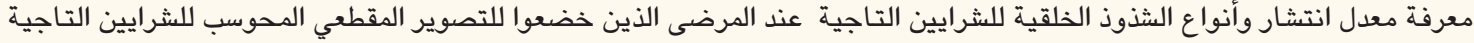

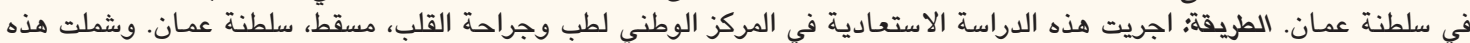

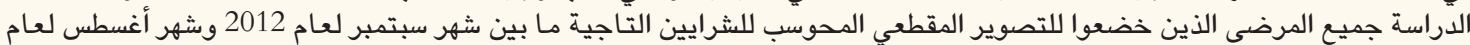

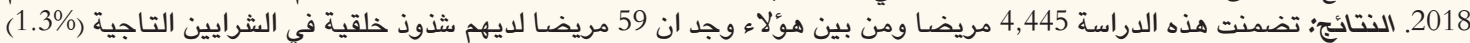

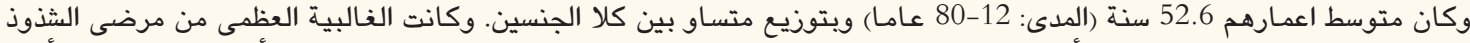

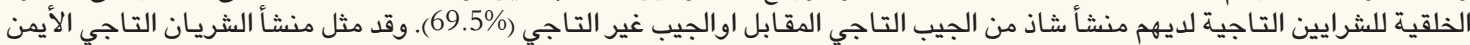

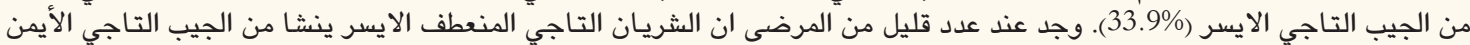

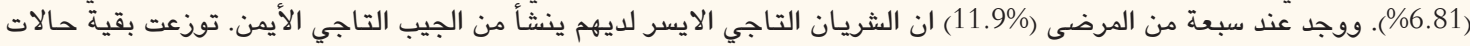

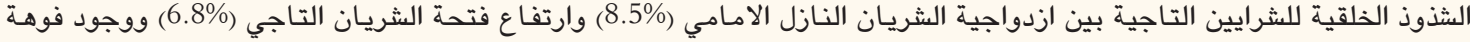

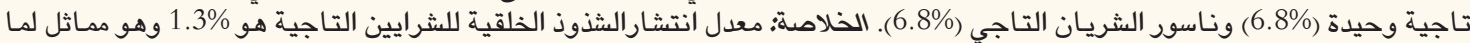

هو موجود في الادبيات الطبية.

$$
\text { الكلمات المفتاحية: تشوهات الأوعية التاجية؛ التصوير المقطعي المحوسب للاوعية الدموية؛ معدل انتشار؛ عمان. }
$$

\section{ADVANCES IN KNOWLEDGE}

The findings of this study demonstrate that there is no significant difference in the prevalence and spectrum of coronary artery anomalies (CAAs) between this study's population and the rest of the world.

\section{Application to Patient Care}

This study highlights the importance of utilising coronary computed tomography angiography as a robust non-invasive test for evaluating CAAs. 
C ORONARY ARTERY ANOMALIES (CAAs) ARE uncommon congenital abnormalities with a prevalence of $0.2-2 \%$ in the general population. ${ }^{1-5}$ CAAs encompass a spectrum of anomalies including abnormalities of origin, course, number, structure and termination of the coronary arteries. ${ }^{6}$ Most patients with CAAs are asymptomatic; however, some CAAs have been linked to ischaemic heart disease, syncope and sudden cardiac death. ${ }^{7-9}$ CAAs are generally detected incidentally on autopsy, conventional coronary angiography (CCA) or through coronary computed tomography angiography (CCTA). Although CCA is the gold standard for assessing contrary arteries, it is an invasive procedure and has limited ability to demonstrate the anatomy of complex CAAs. In contrast, CCTA is non-invasive and can show complex anatomy. ${ }^{1,2,10}$ The National Heart Centre, Muscat, Oman, is a tertiary cardiac centre which receives referrals from all of Oman. This study aimed to assess the prevalence and spectrum of CAAs in Oman's general population.

\section{Methods}

A total of 4,445 consecutive patients who underwent CCTA at the National Heart Centre, from September 2012 to August 2018 were included. The indications for performing CCTA were chest pain to exclude coronary artery disease (CAD), assessment of coronary artery grafts or stents, cardiomyopathy, evaluation for congenital heart disease, evaluation of syncope and pre-cardiac surgery assessment. Patients were excluding from CCTA if they had a history of allergy to iodinated contrast material, impaired renal function defined as an estimated glomerular filtration rate of $<45 \mathrm{~mL} / \mathrm{min} / 1.73 \mathrm{~m}^{2}$, an inability to follow breathing instructions, an uncontrolled heart rate, cardiac arrhythmia and severe coronary calcification on calcium score scan. Patients with myocardial bridging (MB) were excluded as some authors considered $\mathrm{MB}$ to be a normal variant, whereas others considered it to be an anomaly. In addition, there is a lack of clarity regarding its definition in the literature. ${ }^{11-13}$

Prior to the CCTA, participants received an electrocardiogram (ECG) and heart rate and blood pressure were checked. Procedure preparation included the oral administration of $25-100 \mathrm{mg}$ of atenolol with a baseline heart rate $>70$ beats $/ \mathrm{min}$ in order to lower the heart rate. Sublingual nitroglycerine $(0.8 \mathrm{mg})$ was administered to all patients one minute prior to injecting $60-75 \mathrm{~mL}$ of contrast followed by $30 \mathrm{~mL}$ of saline solution at a rate of $6 \mathrm{~mL} / \mathrm{second}$, unless it was contraindicated. The CCTA was performed using a dual source 256 slice $(2 \times 128)$ scanner $($ SOMATOM
Definition Flash, Siemens AG), a rotation time of 280 minutes and dual source 384 $(2 \times 192$; SOMATOM Force, Siemens AG, Berlin and Munich, Germany) with a rotation time of 250 minutes. All scans started with a topogram followed by a prospective ECG-gated nonenhanced computed tomography (CT) scan at a $75 \%$ R-R interval. Subsequently, a contrast-enhanced scan was performed where an ECG-gated prospective or retrospective scan with a slice thickness of $0.6 \mathrm{~mm}$ was acquired during breath holding after inspiration. The scan parameters were adjusted automatically or manually to acquire the best quality image with the lowest radiation dose.

Data from the scanners were sent to separate image processing work stations (Syngo.via, Siemens AG) and analysed by three cardiothoracic radiologists with three, six and nine years of experience. Coronary arteries were assessed for atherosclerotic disease, anomalous origins, courses and terminations. Patients with CAAs were selected and images were again reviewed by a single radiologist before inclusion in the study.

The Scientific Research Committee of the Royal Hospital, Muscat, Oman approved this study (SRC\#53/ 2018) and waived informed consent.

\section{Results}

In the current study, the prevalence rate of patients with CAAs was $1.3 \%$ [Table 1]. The baseline clinical characteristics of these patients are shown in Table 2.

Anomalous origin of the coronary artery from the opposite or non-coronary sinus (ACAOS) was the most common CAA. Right coronary artery (RCA) arising from the left coronary sinus (LCS) was the most common anomaly (33.9\%) [Figures $1 \mathrm{~A}$ and B]. The RCA arose from the non-coronary sinus (NCS) in two patients (3.4\%) [Figures $1 \mathrm{C}$ and D]. In all patients, the anomalous RCA arose from the LCS and then passed between the aortic root and the pulmonary artery taking an interarterial course. One patient underwent deroofing surgery and another patient refused to undergo surgery. The second most common type (18.6\%) of ACAOS was a left circumflex artery (LCX) originating from the right coronary sinus (RCS) or RCA with a retro-aortic course.

Five patients $(8.5 \%)$ had anomalous origin of the left main coronary artery (LMCA) from the RCS and two patients had an interarterial course [Figures $2 A$ and $B$ ]. One patient underwent a coronary artery bypass surgery and one patient refused surgery. Three patients with anomalous LMCA from the RCS had a transseptal course [Figures $2 \mathrm{C}$ and D]. 
Table 1: Prevalence and spectrum of coronary artery anomalies in Omani patients undergoing coronary computed tomography angiography $(\mathrm{N}=59)$

$\begin{array}{cc}\text { Coronary artery anomaly } \quad \mathrm{n}(\%) & \begin{array}{c}\text { Percentage } \\ \text { among total } \\ \text { sample } \\ (\mathrm{n}=4,445)\end{array}\end{array}$

Anomalous origin from opposite or NCS with anomalous course

RCA arising from the LCS

$20(33.9)$

0.450

with interarterial course

$11(18.6)$

0.045

LMCA arising from the RCS

$3(5.1)$

LMCA arising from the RCS

0.076

with transseptal course

$2(3.4)$

0.045

LMCA arising from the RCS

RCA arising from the NCS

0.045

LMCA from the NCS

0.022

Multiple ostia

Absent left main trunk with

LAD and LCX originating

separately from the aorta

Single coronary ostium

High take-off

LMCA

0.045

RCA

Dual LAD anomaly

0.076

0.110

CAF

4. (6.8)

0.089

$N C S=$ non-coronary sinus; $R C A=$ right coronary artery; $L C S=$ left coronary sinus; $L C X=$ left circumflex artery; $R C S=$ right coronary sinus; $L M C A=$ left main coronary artery; $L A D=$ left anterior descending artery; $C A F=$ coronary artery fistula.

Table 2: Baseline characteristics of Omani patients with coronary artery anomalies who underwent coronary computed tomography angiography $(\mathrm{N}=59)$

$\begin{array}{lc}\text { Characteristic } & \mathbf{n}(\%) \\ \text { Mean age in years (range) } & 52.6(12-80) \\ \text { Male:female ratio } & 30: 29 \\ \text { Presenting symptoms } & \\ \text { Typical chest pain } & 13(22) \\ \text { Atypical chest pain } & 28(47.5) \\ \text { Syncope } & 2(3.4) \\ \text { Dyspnoea } & 12(20.3) \\ \text { Palpitation } & 9(15.3) \\ \text { Risk factors } & \\ \text { Diabetes } & 18(30.5) \\ \text { Hypertension } & 24(40.7) \\ \text { Dyslipidaemia } & 7(11.9) \\ \text { Underlying cardiac problem } & \\ \text { Dilated cardiomyopathy } & 5(8.5) \\ \text { Previous myocardial infarction } & 1(1.7)\end{array}$

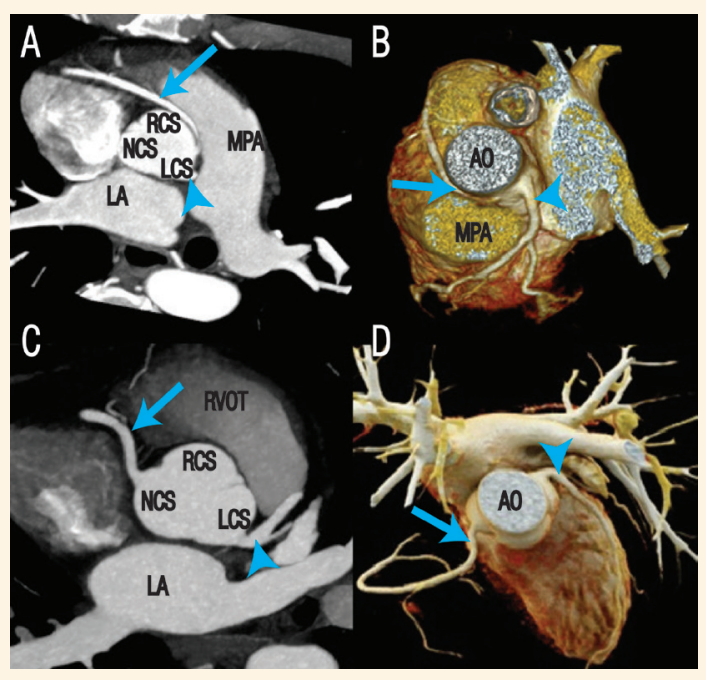

Figure 1: Axial maximal intensity projection via coronary computed tomography angiography imaging (A \& C) and three-dimensional volume rendering (B \& D) showing (A \& B) the right coronary artery (arrow) arising from the left coronary sinus before it courses to the right between the main pulmonary artery and the aorta and showing (C \& D) the right coronary artery (arrowhead) arising from the non-coronary sinus.

$R C S=$ right coronary sinus; $N C S=$ non-coronary sinus; $M P A=$ main pulmonary artery; $L C S=$ left coronary sinus; $L A=$ left atrium; $A O=$ aorta; $R V O T=$ right ventricular outflow tract.

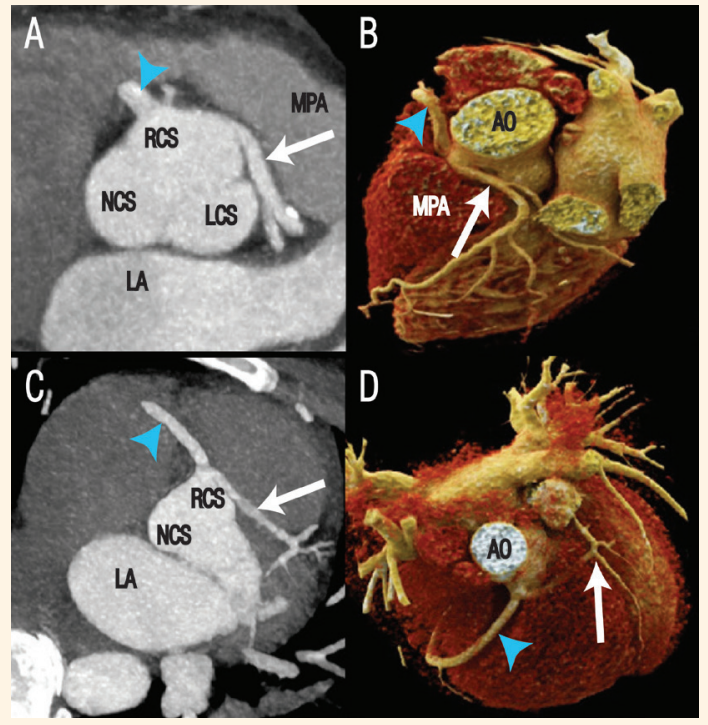

Figure 2: Axial maximal intensity projection via coronary computed tomography angiography imaging $(\mathbf{A} \& \mathbf{C})$ and three-dimensional volume rendering (B \& D) showing (A \& B) the left main coronary artery (arrow) arising from the right coronary sinus before it courses to the left between the main pulmonary artery and the aorta and showing (C \& D) the left main coronary artery (arrow) arising from the right coronary sinus before it courses to the left through the interventricular septum. The right coronary artery is indicated by the arrowhead.

$R C S=$ right coronary sinus; $M P A=$ main pulmonary artery; $N C S=$ noncoronary sinus; $L C S=$ left coronary sinus; $L A=$ left atrium; $A O=$ aorta. 


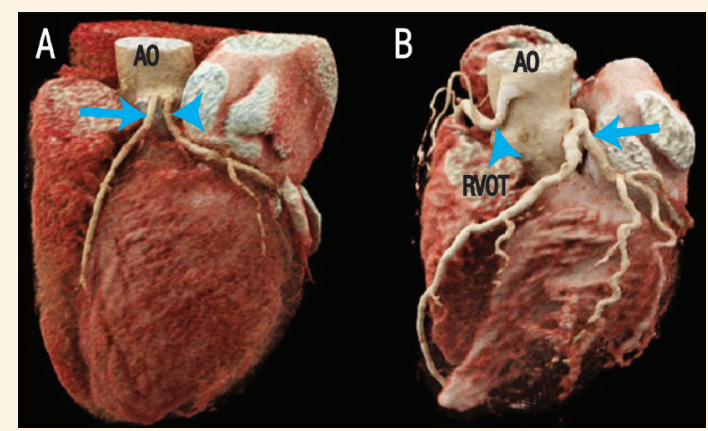

Figure 3: Three-dimensional volume-rendered coronary image showing (A) the separate origin of the left anterior descending artery (arrow) and the left circumflex artery (arrowhead) from the left coronary sinus and (B) the anomalous origin from the right coronary artery (arrowhead) from the aorta above the sinotubular junction.

$A O=$ aorta; $R V O T=$ right ventricular outflow tract.

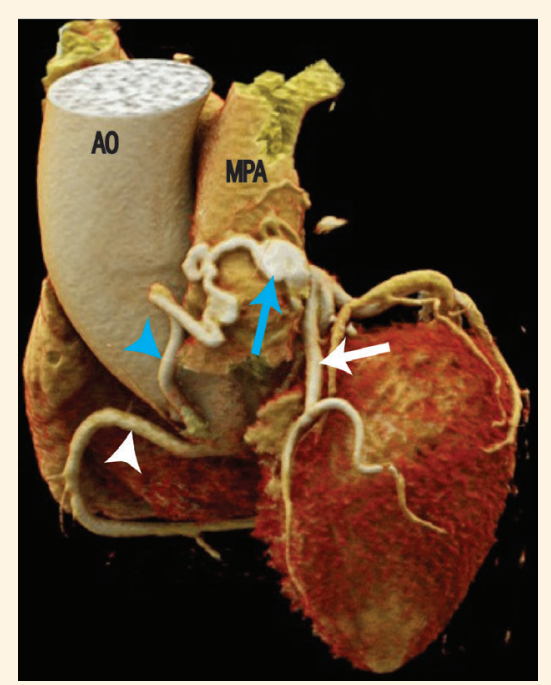

Figure 4: Three-dimensional volume rendered coronary computed tomography angiography image showing a tortuous vessel (blue arrowhead) arising from the right coronary artery (white arrowhead). The tortuous vessel passes anterior to the main pulmonary artery and forms a small aneurysm (blue arrow) before it enters the main pulmonary artery distal to the valve. The left anterior descending artery is marked by the white arrow.

$A O=$ aorta; $M P A=$ main pulmonary artery.

LMCA was absent in one patient (1.7\%) with the left anterior descending (LAD) coronary artery and LCX arising separately from the LCS [Figure 3A]. Three patients (5.1\%) had high take-off RCA [Figure 3B]. Four patients (6.8\%) had coronary artery fistulas (CAFs) in the forms of a fistula connecting the RCA to the main pulmonary artery (MPA) [Figure 4], a fistula between the left anterior descending artery (LAD) or the MPA, which is a complex fistula that connects the RCA, the LAD and a bronchial artery. One patient had a complex fistula between the RCA, LMCA, LAD and MPA.

\section{Discussion}

CAAs are part of a spectrum of uncommon coronary artery congenital anomalies. ${ }^{13}$ In the literature, discrepancies in the prevalence of CAAs are largely due to the inclusion or exclusion of $\mathrm{MB}$ due to the fact that some authors consider $\mathrm{MB}$ as a normal variant, whereas others consider it an anomaly. ${ }^{12,14,15}$ When MB is excluded, the prevalence of CAAs ranges between 0.5-3.1\%; however, when $\mathrm{MB}$ is included, prevalence increases to $7.9-18.4 \%{ }^{3}$ In the current study, the prevalence of CAAs, excluding MB, was $1.3 \%$ which falls within the reported range in the literature. ${ }^{3,5,11,16}$ To the best of the authors' knowledge, this study is the first to estimate the prevalence and spectrum of CAAs in the general Omani population.

CCA can be used to detect CAAs, although it is an invasive procedure and has a risk of complications. ${ }^{17}$ However, CCTA is a non-invasive test that has recently become the gold standard for detecting and characterising CAAs. CCTA can precisely delineate the course of the anomalous artery and provide three-dimensional information about the relation of anomalous to other cardiovascular structures, namely cardiac chambers and major arteries. ${ }^{18-20}$

CAAs can be categorised based on the origin, course, number and termination of the coronary arteries. ${ }^{6}$ In the current study, ACAOS was the most common CAA (69.5\%) which was similar to reports from previous studies. ${ }^{7,11,20,21}$ ACAOS can be classified into four groups: 1) RCA arising from the LCS, 2) LCA arising from the RCS, 3) LCX or LAD arising from the RCS and 4) LCA or RCA arising from the NCS. ${ }^{6,22}$ The course of the anomalous artery can be interarterial between the aorta and the MPA, anterior to the MPA, retroaortic or transseptal through the interventricular septum., ${ }^{5,9,13,16}$ Of these courses, the most clinically significant anomaly is the interarterial course because it is strongly associated with sudden death, particularly in young competitive athletes. ${ }^{23}$ Although not fully understood, the assumed mechanism of ischaemia in an anomalous artery with an interarterial course is that the anomalous artery is squeezed between the aorta and the MPA. ${ }^{11}$ Therefore, patients with an interarterial course should be treated; however, many patients with these anomalies are asymptomatic. Moreover, there are difficulties implicit in routine examinations and clinical testing for these anomalies. In such cases CCTA is an important diagnostic tool as it can differentiate between interarterial and transseptal courses with high spatial and temporal resolution., ${ }^{9,16}$ However, a disadvantage of using CCTA is the radiation that accompanies it; however, the new generation of multidetector scanners has much lower radiation compared to older generations. ${ }^{24}$ 
There are three different treatment options for patients with interarterial anomalous arteries: 1) medical treatment, 2) angioplasty and 3) surgical repair. ${ }^{25}$ In the current study, all 20 patients with anomalous RCA from the LCS had an interarterial course.

Multiple coronary artery ostia is either due to the separate origins of the RCA and conus branch from the aorta or the absent LMCA with the LCX and LAD arising separately from the aorta. The prevalence of the absence of LMCA ranges from $0.5-8 \% .^{5}$ In this study's sample, the prevalence was lower $(0.03 \%)$ and only one patient had no LMCA and separate ostia of the LAD and LCX. Multiple ostia allow alternative collateral supplies in patients with proximal CAD; however, these can cause technical difficulties in cannulation during invasive coronary angiography. ${ }^{11,13,26}$

A single coronary ostium is an extremely rare congenital anomaly characterised by a single artery arising with a single ostium from the aorta. It is seen in only $0.0024-0.044 \%$ of the population. ${ }^{6}$ Patients with a single coronary artery are at increased risk for sudden death if a major coronary branch has an interarterial course between the pulmonary artery and the aorta. ${ }^{27}$ Four of the current patients (6.8\%) had single coronary ostia which originated from the RCS.

A high take-off CAA is a coronary artery which arises from the aortic wall $0.5 \mathrm{~cm}$ above the sinotubular junction. ${ }^{6}$ Although this anomaly is benign, it can cause technical difficulties of coronary artery cannulation during conventional angiography. Moreover, cardiac surgeons should be aware of this anomaly prior to cardiac surgery to avoid damaging the anomalous artery while cross-clamping the aorta. ${ }^{5,16}$ In the current study, four patients $(6.8 \%)$ had high take-off coronary arteries, one patient $(1.7 \%)$ had high take-off of the LMCA and three (5.1\%) had high take-off RCA.

Dual LAD is a rare congenital anomaly which is defined by the presence of short and long LADs which supply the course of the LAD. ${ }^{28}$ It is traditionally classified into four types based on the origin, course and termination of the short and long LADs; however, CCA has led to recognition of other variants. To date, eleven types of dual LAD variants have been identified. ${ }^{29}$ Awareness of dual LAD variants is crucial for interpreting cardiac CTs in patients with dual LAD anomalies and for planning percutaneous and surgical reperfusion strategies. Five of the patients (8.5\%) in the current study had dual LADs.

CAFs are defined by abnormal communication between a coronary artery and another structure such as a heart chamber, the MPA or the coronary sinus. ${ }^{16,30}$ Small CAFs are usually asymptomatic and detected incidentally on echocardiography, coronary arterio- graphy or CCTA performed for other reasons. However, large CAFs can lead to the 'steal phenomenon' which can lead to ischaemia due to diminished blood supply to the portion of the myocardium supplied by the involved coronary artery. CAFs are seen in $0.05-0.25 \%$ of patients undergoing conventional angiography. ${ }^{30} \mathrm{In}$ this study, the prevalence of CAFs was $0.089 \%$.

This study had some limitations. This was a single centre experience and some important clinical characteristics of the patients included in this study were not documented due to its retrospective nature. In addition, minor CAAs, including coronary artery ectasia, aneurysm and variant origins of the conus artery were excluded. MB was also excluded due to uncertainty about diagnostic and classification criteria.

\section{Conclusion}

The prevalence of CAAs in Oman was similar to reported figures from earlier studies performed worldwide. In Oman, anomalous origin of the RCA arising from the LCS was the most common type.

\section{CONFLICT OF INTEREST}

The authors declare no conflicts of interest.

\section{FUNDING}

No funding was received for this study.

\section{References}

1. Zukić F, Miljko M, Vegar-Zubović S, Behmen A, Arapović AK. Prevalence of coronary artery anomalies detected by coronary CT angiography in Canton Sarajevo, Bosnia and Herzegovina. Psychiatr Danub 2017; 29:830-4.

2. Smettei OA, Sayed S, Abazid RM. The prevalence of coronary artery anomalies in Qassim Province detected by cardiac computed tomography angiography. J Saudi Heart Assoc 2017; 29:84-9. https://doi.org/10.1016/j.jsha.2016.07.006.

3. Sirasapalli CN, Christopher J, Ravilla V. Prevalence and spectrum of coronary artery anomalies in 8021 patients: A single centre study in South India. Indian Heart J 2018; 70:852-6. https://doi.org/10.1016/j.ihj.2018.01.035.

4. Kardos A, Babai L, Rudas L, Gaál T, Horváth T, Tálosi L, et al. Epidemiology of congenital coronary artery anomalies: A coronary arteriography study on a central European population. Cathet Cardiovasc Diagn 1997; 42:270-5. https://doi.org/10.1002/(SICI) 1097-0304(199711)42:3<270::AID-CCD8>3.0.CO;2-9.

5. Graidis C, Dimitriadis D, Karasavvidis V, Dimitriadis G, Argyropoulou E, Economou F, et al. Prevalence and characteristics of coronary artery anomalies in an adult population undergoing multidetector-row computed tomography for the evaluation of coronary artery disease. BMC Cardiovasc Disord 2015; 15:112. https://doi.org/10.1186/s12872-015-0098-x.

6. Kim SY, Seo JB, Do KH, Heo JN, Lee JS, Song JW, et al. Coronary artery anomalies: Classification and ECG-gated multi-detector row CT findings with angiographic correlation. Radiographics 2006; 26:317-34. https://doi.org/10.1148/rg.262055068. 
7. Garg N, Tewari S, Kapoor A, Gupta DK, Sinha N. Primary congenital anomalies of the coronary arteries: A coronary arteriographic study. Int J Cardiol 2000; 74:39-46. https://doi.org/10.1 016/S0167-5273(00)00243-6.

8. Cox ID, Bunce N, Fluck DS. Failed sudden cardiac death in a patient with an anomalous origin of the right coronary artery. Circulation 2000; 102:1461-2. https://doi.org/10.1161/01.CIR.1 02.12 .1461 .

9. Cheezum MK, Ghoshhajra B, Bittencourt MS, Hulten EA, Bhatt A, Mousavi $\mathrm{N}$, et al. Anomalous origin of the coronary artery arising from the opposite sinus: Prevalence and outcomes in patients undergoing coronary CTA. Eur Heart J Cardiovasc Imaging 2017; 18:224-35. https://doi.org/10.1093/ehjci/jev323.

10. Al Umairi RS, Al Kindi F, Al Busaidi F. Anomalous Origin of the Left Coronary Artery from the Pulmonary Artery: The Role of Multislice Computed Tomography (MSCT). Oman Med J 2016; 31:387-9. https://doi.org/10.5001/omj.2016.77.

11. Namgung J, Kim JA. The prevalence of coronary anomalies in a single center of Korea: Origination, course, and termination anomalies of aberrant coronary arteries detected by ECGgated cardiac MDCT. BMC Cardiovasc Disord 2014; 14:48. https://doi.org/10.1186/1471-2261-14-48.

12. Möhlenkamp S, Hort W, Ge J, Erbel R. Update on myocardial bridging. Circulation 2002; 106:2616-22. https://doi.org/10.11 61/01.CIR.0000038420.14867.7A.

13. Kim PJ, Hur G, Kim SY, Namgung J, Hong SW, Kim YH, et al. Frequency of myocardial bridges and dynamic compression of epicardial coronary arteries: A comparison between computed tomography and invasive coronary angiography. Circulation 2009; 119:1408-16. https://doi.org/10.1161/circulationaha.108.788901.

14. Leschka S, Koepfli P, Husmann L, Plass A, Vachenauer R, Gaemperli $\mathrm{O}$, et al. Myocardial bridging: Depiction rate and morphology at CT coronary angiography--Comparison with conventional coronary angiography. Radiology 2008; 246:754-62. https://doi.org/10.1148/radiol.2463062071.

15. Hwang JH, Ko SM, Roh HG, Song MG, Shin JK, Chee HK, et al. Myocardial bridging of the left anterior descending coronary artery: Depiction rate and morphologic features by dual-source CT coronary angiography. Korean J Radiol 2010; 11:514-21. https://doi.org/10.3348/kjr.2010.11.5.514.

16. Gräni C, Benz DC, Schmied C, Vontobel J, Possner M, Clerc OF, et al. Prevalence and characteristics of coronary artery anomalies detected by coronary computed tomography angiography in 5634 consecutive patients in a single centre in Switzerland. Swiss Med Wkly 2016; 146:w14294. https://doi.org/10.4414/ smw.2016.14294

17. Tavakol M, Ashraf S, Brener SJ. Risks and complications of coronary angiography: A comprehensive review. Glob J Health Sci 2012; 4:65-93. https://doi.org/10.5539/gjhs.v4n1p65.

18. Schmitt R, Froehner S, Brunn J, Wagner M, Brunner $\mathrm{H}$, Cherevatyy $\mathrm{O}$, et al. Congenital anomalies of the coronary arteries: Imaging with contrast-enhanced, multidetector computed tomography. Eur Radiol 2005; 15:1110-21. https://doi.org/10.1007/s0 0330-005-2707-z.
19. John J, Miller JH, Leslie SJ. A case of anomalous coronary artery origin: The role of computerised tomography. SAGE Open Med Case Rep 2016; 4:2050313X16628729. https://doi.org/10.1 $177 / 2050313 X 16628729$

20. Fujimoto S, Kondo T, Orihara T, Sugiyama J, Kondo M, Kodama T, et al. Prevalence of anomalous origin of coronary artery detected by multi-detector computed tomography at one center. J Cardiol 2011; 57:69-76. https://doi.org/10.1016/j.jjcc.2010.10.006

21. Xu H, Zhu Y, Zhu X, Tang L, Xu Y. Anomalous coronary arteries: Depiction at dual-source computed tomographic coronary angiography. J Thorac Cardiovasc Surg 2012; 143:1286-91 https://doi.org/10.1016/j.jtcvs.2011.11.025.

22. Amado J, Carvalho M, Ferreira W, Gago P, Gama V, Bettencourt N Coronary arteries anomalous aortic origin on a computed tomography angiography population: Prevalence, characteristics and clinical impact. Int J Cardiovasc Imaging 2016; 32:983-90. https://doi.org/10.1007/s10554-016-0849-5.

23. Basso C, Maron BJ, Corrado D, Thiene G. Clinical profile of congenital coronary artery anomalies with origin from the wrong aortic sinus leading to sudden death in young competitive athletes. J Am Coll Cardiol 2000; 35:1493-501. https://doi.org/10.1016/S0 735-1097(00)00566-0.

24. Sun Z, Choo GH, Ng KH. Coronary CT angiography: Current status and continuing challenges. Br J Radiol 2012; 85:495-510. https://doi.org/10.1259/bjr/15296170.

25. Wu GR, Saini A, Ahmed I, Finch C. Interarterial course of anomalous right coronary artery: Pathophysiology, diagnosis, and treatment. Radiol Case Rep 2017; 12:664-7. https://doi.org/10.1016/ j.radcr.2017.06.006

26. Sohrabi B, Habibzadeh A, Abbasov E. The incidence and pattern of coronary artery anomalies in the north-west of Iran: A coronary arteriographic study. Korean Circ J 2012; 42:753-60. https://doi.org/10.4070/kcj.2012.42.11.753

27. Said SA, de Voogt WG, Bulut S, Han J, Polak P, Nijhuis RL, et al Coronary artery disease in congenital single coronary artery in adults: A Dutch case series. World J Cardiol 2014; 6:196-204. https://doi.org/10.4330/wjc.v6.i4.196.

28. Bozlar U, Uğurel MS, Sarı S, Akgün V, Örs F, Tașar M. Prevalence of dual left anterior descending artery variations in CT angiography. Diagn Interv Radiol 2015; 21:34-41. https://doi.org/10.5152/dir.2 014.14275

29. Al-Umairi RS, Al-Kindi FA, Al-Tai SA. A new variant of dual left anterior descending artery anomaly: Type XI. 2018; 18:e386-8. https://doi.org/10.18295/squmj.2018.18.03.021.

30. Zenooz NA, Habibi R, Mammen L, Finn JP, Gilkeson RC Coronary artery fistulas: CT findings. Radiographics 2009; 29:781-9. https://doi.org/10.1148/rg.293085120. 